\title{
Cluster Technologies in Regional Development Control System
}

\author{
Anokhina, M.Y. \\ Candidate of Economic Sciences, Associate Professor of the Department of \\ Corporative Management of Plekhanov Russian University of Economics \\ Email: marina_anokhina@maill.ru
}

Mochal'nikov, V.N.

Doctor of Economic Sciences, Professor of the Department of Corporative Management of Plekhanov Russian University of Economics, 36, Stremyanny lane, Moscow, 117997 Russian Federation

Email:mvn928@gmail.com

Doi:10.5901/mjss.2015.v6n3s2p546

\section{Abstract}

An article presents the results of research based on influence of cluster technologies on the process of social-and-economic development of the region. Foreign and local experience of clustering has been analyzed in economics; the main advantages of cluster structures providing upgrade of competitive ability of the regions and innovative area development have been shown. Restrictions of cluster usage have been defined in Russian practice. Based on the example of creation and development of North Caucasian tourist cluster, problems of cluster technologies usage have been revealed in management of regional development and the main of them is the problem of staffing. To solve this problem the authors have developed a model of a field educational cluster in the sphere of tourism and service, which is based on the estimate of the amount of personnel resources and existing educational potential of the region. In addition they recommended an organizational and functional structure of a corporate university and created an interaction model between assessment center and certification with executive bodies, educational facilities and interested organizations. Realization of suggested events will contribute a successful fulfillment of one of the biggest projects in Russia based on cluster technologies usage.

Keywords: cluster, cluster technologies, regional development, North Caucasian tourist cluster, field educational cluster, corporate university, center of assessment and certification of qualifications.

\section{Introduction}

Regionalization processes that are typical for nowadays economic situation are responsible for necessity of creation of regional development control system that, on the one hand, must be orientated on maximization of region potential usage and, on the other hand - provide positive national economic dynamics. The study of regional development problem made it possible to establish the usage of cluster technologies as one of the directions of its solution.

The choice of where clustering should be focused on those sectors whose potential can not only provide regional and national growth, but also taking into account modern trends to achieve the balance of the national economy, reducing its dependence on commodity exports. The tourism industry refers to these areas.

The share of tourism services in the international market reaches 30\%. Every year the volume of investments in tourism increased by $35 \%$, it is concentrated to $9 \%$ of the total global capital. By 2020 , projected to nearly double the current world tourist traffic up for 2 billion per year.

Based on the analysis of existing and potential future forecast tourist flows among the most attractive destinations in addition to the existing Russian centers of gravity are recognized North Caucasus, the Far East (Kamchatka), Altai and Baikal. In this regard, the creation in 2010 of "Resorts of the North Caucasus", integrating the process of formation of tourist and recreational cluster in the North Caucasus, is the most important step of the Government of Russia in this direction.

Inadequate staffing activity tourism-recreation cluster should be regarded as one of the constraints to the successful implementation of the project of the North Caucasus. Therefore, the authors have developed and proposed a mechanism of cluster formation through the creation of its educational structure of the cluster.

The composition of the education cluster has mobile character while maintaining the core members of the cluster space and their active interaction with stakeholders beyond that will help to change the territorial organization of industry 
resources of vocational education in the region in the direction of the staffing problem, as the main limitations of the cluster and regional dynamics.

Results and conclusions the study brought to the level of specific science-based regulations. Proposed areas of management development cluster formations in the tourism and recreation sector in the region can be used in the formation and management of cluster structures in other areas. The results can be the basis of the development of integrated regional development programs. Offer may be useful for the Ministry of Economic Development of Russia, JSC "Special Economic Zones" and JSC "Resorts of the North Caucasus".

\section{Theoretical Aspects of Clustering in the Economy}

A well-known specialist of clustering issues in economics and competition issues, professor of Harvard business school, M. Porter (2002) has defined that cluster formation in the field obtains a strategic importance for the country. He defines cluster as "geographically based groups of interrelated companies, specialized suppliers, service providers, companies in the relevant fields, and also organizations that are related to their activities (for instance, universities, agencies for standardization, commercial associations) in specific spheres that are competing and at the same time lead collaborative work".

In the process of his investigation M. Porter (2002) has analyzed competitive abilities of more than 100 fields in 10 countries. It was found that the most competitive transnational companies are not usually spread across different countries randomly, but have a tendency to concentrate on one region of the country. The most important observation of M. Porter (2002) is: the more clusters in separate country are developed, the higher is the social standard of living and the competitive ability of the company.

At the level of several states there were engineered programs, strategic base of which were clusters. A striking example of organically appeared cluster is "Silicon valley" that consists of computer technics and software companies, Stanford and California universities.

The study of effects on processes of cluster structures regional development are typical for works of S. Rosenfeld (1997), who defined the principal distinctions of cluster from network organizations and pointed out interdependence of subject-counterparties as a criterial factor of joining of companies into cluster.

Enright M (2000), defining cluster as a combination of firms-participants that are close to each other in terms of location considers them as an instrument of regional development and completes classification with groups "politically controlled clusters" that don't have critical mass, but that are chosen by the government for support and "preferred clusters" that don't have neither critical mass nor other source of privileges that might contribute to organic development.

A range of authors consider clusters as instruments for raising of region competitive ability by means of raising of competitive ability of participants of integrated structure. Bergman E.M. and Feser E.J (1999) define cluster as a group of commercial enterprises and noncommercial organizations which find membership in a group an important element of increasing of individual competitive ability.

T. Anderssonand others (2004)deal with the clustering issue defining it as a "process of collective location of firms and characters inside concentrated geographical region". Authors relate cluster with cooperation around specific functional niche and establishment of close interrelations and working alliances for reinforcement of collective competitive abilities of joint firms. These authors specify such cluster characteristics: specialization, innovativeness, diversification of participants and life cycle.

A. Markusen (1996), while studying the problem of clustering in a part of participants, their behavior, interrelations and conditions in specific area, points out the following types of clusters:

«Marshall» clusters that consist of small firms of the same field and use economies of scope;

«radical» clusters that have one or few dominant big, vertically integrated firms that are surrounded by suppliers;

«satellite» clusterthatcombinesindependentcompaniesthatareorientatedondelivery to external, towards cluster, enterprise;

cluster, «bound by the state», in the structure of which dominate one or few governmental institutes.

Specialists of Finland economics research institute (ETLA) have identified a cluster frame on the territory of their country, which consists of fields with a stable export and a flow-in of foreign investments - forest, informational and telecommunicational, metallurgic, energetical, business services, healthcare, machine building, food and constructional.

While systematizing experience of foreign countries upon usage of cluster approach it is necessary to point out that clustering, as a system in a foreign practice, is characterized by its diversity and lack of universalism that is caused by field and national factors. There can be emphasized 12 general criteria of cluster: opportunities according to research and 
development, skills of work force, development of labor potential, access to specialized services, suppliers' proximity, capital availability, relationships with equipment suppliers, associated structures, network formation intensity, entrepreneurial vigor, innovations and training, collective vision and management. Specialized work force is highlighted as a critically vital factor. That is why specialized workforce training is obligatory and the most important element of regional cluster programs.

Unfortunately, the usage of cluster technologies as a tool for control of regional development is limited in local practice, which is cause the necessity of development of methodological and practical approaches to creation and functioning of clusters on specific territory, that will contribute to positive economic dynamics and increase of competitive ability of regional systems.

Features clustering in tourism and recreational services to ensure development of the regions at the moment are poorly understood. Modern Strategy and Tactics formation of the economic potential of the region requires a rethinking of the nature of the process of clustering and ordering directions of its development from a regional perspective.

\section{Tendencies of Cluster Technologies Development in Russia}

Cluster structures that are formed in region make it possible to reinforce processes if economic dynamics, contribute to increase of regional competitive ability and provide innovative development of territories.

Clusters activate entrepreneurship in region, i.e. a high level of specialization as a characteristic feature of cluster structure stimulate formation of new firms that are orientated on specific market niche and reduces entry barriers for new participants in cluster formation due to predominance of horizontal integrated relations.

The general economic stability of enterprise that are included in cluster, is reached by means of access to resources, transfer of knowledge and technologies, partner relationships, formation of special property rights configurations for different objects that ensure more efficient their usage. By the same token, improving stability of economic entities of the region creates basis for regional economic dynamics. Tax revenue to the regional budget is increasing, material and technical resources of the region are improving, and their investment attractiveness is increasing. It is important to mention the opportunity of formation of complex knowledge by means of combining a potential of fundamental science, RTD, manufacture and sale in a cluster.

In modern conditions, dividing regional economics on fields within the bounds of traditional approach to management loses its efficacy, i.e. interrelations of firms and organizations which have multisectoral nature come to the fore. Therefore, it is necessary to control relations, which makes it possible to provide cluster approach. In such a case, there is an increase of interrelation efficacy not only of technologically bounded organizations, but partner interrelations between business, trade associative structures, research and educational facilities are provided.

In conditions of limited abilities of regional bodies to exercise vital functions on strategic development of the territories, on location of production powers, multisectoral interrelation, and balance of regional economic structure; cluster technologies can become a basis of regional economic policy that is efficiently integrated into national economic system. In this way, a new technically production and socio-cultural structure will be formed.

Nowadays, an approach to regional development that is based on clusters finds more and more understanding from Russia. Six regions have already have clusters that are included in the list The European Cluster Collaboration Platform (ECCP) (table 1).

Table 1 - Russian clusters from The European Cluster Collaboration Platform (ECCP) ${ }^{1}$

\begin{tabular}{|l|l|l|}
\hline Region & Name of cluster & Sphere of activities \\
\hline \multirow{5}{*}{ The Penza region } & Penza confectionary cluster & Agrofood sphere \\
\cline { 2 - 3 } & Biomedical cluster of the Penza region & Biotechnologies \\
\cline { 2 - 3 } & $\begin{array}{l}\text { Penza innovative cluster of universal components and measurement } \\
\text { systems }\end{array}$ & Electronics, electronic equipment \\
\cline { 2 - 3 } & Penza vitreous cluster & Optics and photonics \\
\cline { 2 - 3 } & Penza tourist cluster & Tourism \\
\cline { 2 - 3 } & Furniture cluster of Penza region & Woodworking industry, furniture industry \\
\hline Republic of Tatarstan & Sinarskyi tube plant & Car Manufacturing \\
\hline Samara region & Volgian car cluster & Chemistry \\
\hline Sverdlovsk region & Ural pharmaceutical cluster & Healthcare, medical technique \\
\cline { 2 - 3 } & Yekaterinburg medical cluster & Informational and communicational technologies \\
\cline { 2 - 3 } & Ural IT Cluster & Transport infrastructure \\
\cline { 2 - 3 } & Ural locomotives & \\
\hline
\end{tabular}

${ }^{1}$ The European Cluster Collaboration Platform (ECCP) . URL:http://www.clustercollaboration.eu/cluster-organisation. 


\begin{tabular}{|l|l|l|}
\hline \multirow{5}{*}{ Tomsk region } & Cluster «Fluoride technologies» & Chemistry \\
\cline { 2 - 3 } & Cluster «Solid microwave electronics» & Electronics, electronic equipment \\
\cline { 2 - 3 } & Cluster «West-Siberian atomic-industrial alliance» & Energetics \\
\cline { 2 - 3 } & Cluster «Informational technologies» & Informational-communicative technologies \\
\cline { 2 - 3 } & Wood cluster & $\begin{array}{l}\text { Woodworking industry, paper-pulp industry, furniture } \\
\text { production }\end{array}$ \\
\cline { 2 - 3 } & Innovative territorial cluster «Pharmaceutics and medical techniques» & Healthcare, medical technique \\
\hline Kaluga region & NPO "Kaluga pharmcluster" & Biopharmaceutics \\
\hline
\end{tabular}

Institutional cluster development platform in regions with spontaneous national politics in this sphere is quite actively formed. As examples can be Centers of cluster development in Tatarstan, Astrakhan, Voronezh, Tomsk and Kurgan regions; Center of innovative development and cluster initiatives of Samara region.

However, these initiatives, immensity and formation rate of cluster structures don't let Russia occupy rightful place in ranking according to the level of cluster development in the country. These ranking is built within the frame of informative base according to global competitive ability Index of the worldwide economic forum (table 2). Russian position has significantly worsened - whereas in $2010-2011$ it had $87^{\text {th }}$ place, now this country occupies $118^{\text {th }}$ place. The quantitative estimate of cluster development in country in seven-point scale (where 1 means that there is lack of welldeveloped clusters in the country and 7 means that they are presented in many regions) in the last 5 years didn't pass 3,2 points.

Table 4 - Russian comparison according to level of cluster development in calculation system of global competitive ability Index of the Worldwide economic forum (Global Competitiveness Index-GCI) ${ }^{2}$

\begin{tabular}{|c|c|c|c|c|c|c|c|c|c|c|}
\hline \multirow[b]{2}{*}{ Country } & \multicolumn{2}{|c|}{$2010-2011$} & \multicolumn{2}{|c|}{$2011-2012$} & \multicolumn{2}{|c|}{$2012-2013$} & \multicolumn{2}{|c|}{$2013-2014$} & \multicolumn{2}{|c|}{$2014-2015$} \\
\hline & $\begin{array}{l}\text { Quant. } \\
\text { estimate }\end{array}$ & $\begin{array}{c}\text { Placeinran } \\
\text { king* }\end{array}$ & \begin{tabular}{|c|} 
Quant. \\
estimate
\end{tabular} & 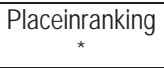 & \begin{tabular}{|c|} 
Quant. \\
estimate
\end{tabular} & $\begin{array}{c}\text { Placeinra } \\
\text { nking* }\end{array}$ & $\begin{array}{l}\text { Quant. } \\
\text { estimate }\end{array}$ & 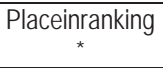 & $\begin{array}{c}\text { Quant. } \\
\text { estimate }\end{array}$ & $\begin{array}{c}\text { Placeinran } \\
\text { king* }\end{array}$ \\
\hline Russia & 3,2 & 87 & 3,2 & 92 & 3,0 & 114 & 3,1 & 124 & 3,1 & 118 \\
\hline Brazil & 4,5 & 23 & 4,5 & 25 & 4,5 & 28 & 4,5 & 26 & 4,6 & 24 \\
\hline Germany & 5,0 & 12 & 4,9 & 13 & 5,1 & 8 & 5,4 & 4 & 5,5 & 3 \\
\hline India & 4,2 & 29 & 4,2 & 31 & 4,5 & 29 & 4,9 & 16 & 4,5 & 27 \\
\hline Italy & 5,5 & 1 & 5,4 & 1 & 5,3 & 2 & 5,5 & 2 & 5,6 & 1 \\
\hline China & 4,7 & 17 & 4,7 & 17 & 4,6 & 23 & 4,6 & 24 & 4,6 & 25 \\
\hline Kazakhstan & 3,2 & 85 & 3,3 & 85 & 3,1 & 110 & 3,1 & 126 & 3,2 & 116 \\
\hline United States & 5,1 & 6 & 5,1 & 9 & 5,0 & 12 & 5,2 & 6 & 5,4 & 5 \\
\hline Japan & 5,4 & 2 & 5,3 & 3 & 5,2 & 5 & 5,2 & 7 & 5,3 & 8 \\
\hline
\end{tabular}

* Index2014-2015 has144 countries; Index2013-2014 has148 countries; Index 2012-2013 has144 countries, Index 20112012 has 142 countries, Index 2010-2011 has 139 countries.

\section{The Main Development Problems of the Regional Tourist Cluster}

The necessity of clustering process activation in regions is obvious, though, it is important to provide concurrence of regional initiatives with national projects. The example of such approach can be complex events concerning creation and development of tourist cluster in North-Caucasian federal district, Krasnodar Krai and the Republic of Adygea. The created cluster structure is complicated in methodological and technological plans of its implementation.

It is designed for the amount of tourist stream of about 10 millions of tourists a year and includes a range of worldclass mountain resorts: «Lagonaki» (Krasnodar Krai and the Republic of Adygea), «Arkhyz» (Karachai-Cherkess Republic), «Elbrus-Bezengi» (Kabardino-Balkar Republic), «Mamison» (the Republic of North Ossetia-Alania), «Matlas» (the Republic of Dagestan), «Tsori» and «Armkhi» (the Republic of Ingushetia). This place must become an up-dated Russian ground for creation of modern competitive regional tourist cluster with powerful motivational nuclear, and the most various list of tourist products among all parties of the Russian Federation that are involved in the project. While developing and realization of North-Caucasian project there are a lot of difficult problems that, primarily, include:

1. Inactivity of small business that lies at the root of business-model of tourism as a sphere of activities. There are no sufficient amount of qualifies staff; there exist traditional concerns about bureaucracy and government machine; value detraction is active. As a result, micro-enterprises of the North Caucasus that can be a base of 
business-model of tourist cluster make up only 2,13\% from the total amount of regional companies, and their turnover is only $2,29 \%$. The problem is subject not only to regional factors, but to national gaps in culture formation of small and medium business.

2. Lack of acceptable balance between risks and profitability, which often becomes a reason of low business interest in project realization. The task of state is to minimize risks that is provided by preferences in taxation sphere - reset of federal part of profit tax (2\%), lowering of regional part to zero is possible (now 18\%), remission of estate, land and transport taxes for up to ten years. In addition, free infrastructure for private investors and token payment for provided land lots.

3. High level of situation criminalization provides limitation of financial possibilities of small and medium business. When there is a subgoal of project - to provide conditions for profitable participation of small and medium business in the project (minimal investments of personal means, structuring of contracting of credits and loans at subsidized interest), in complicated conditions makes the process of its achievement problematical.

4. Project safety as a result of social problems in the region. Reduction of unemployment level, increase of economic stability at cluster functioning will contribute to inhabitants interest in providing safety of guests. It is important to mention that local inhabitants can sometimes provide safety more efficiently than federal power structures. A complex safety system of tourist cluster is engineered and realized within the frame of project, which is presented as an effective means during the period of winter Olympics in Sochi.

5. Underdevelopment of the system formation of request of native consumers for tourist products of cluster. It is necessary to create motivation for regions-suppliers of tourist streams, including development of social tourism. At the same time it is required to involve native trade unions, pension funds, insurance and other structures that have an experience of good influence on direction of tourist streams into the side of their resorts.

6. Insufficient correlation of regional status of project and activities (and often inactivity) of federal center. Such disbalanced moments that keep the process of project realization include a high level of transport rates, which limits native and foreign tourist streams. Besides, due to a high price level, mountain skiing tourism is economically inaccessible for the most part of country population. It is important to point out that integration of North-Caucasian cluster into national economic system is handicapped due to the fact that indexes of social development of Russian regions are still not connected with key project parameters.

7. Considerable staff deficiency of cluster. An existing necessity of the North Caucasus in new work places of about 500 thousands can be reduced to $30 \%$ with the appearance of resorts. Within the frame of cluster, the deficiency of work force is predicted until 2025 in the amount of more than 200 thousands pairs of workers.

It is necessary to mention that problems arising in the process if cluster technologies realization in the NorthCaucasian region are caused, first of all, by gaps in staffing at all organizational levels. Global competition and tourism concentration create a lot of problems for gaining customer's loyalty and for creation of firm competitive advantage on the market of tourist product. Success and competitive ability of tourist direction depend on many factors, the most important of which is human resources (image 1 ).

The quality of work force depends on educational level and practical skills. If people, who are occupied in tourist sector don't have required skills and knowledge and the field can't provide itself with staff of necessary preparation level, negative effect on related branches and potential of economic growth arises as a result. Human resources are important and sensitive part of tourism management due to their role in making contact with visitors as service users.

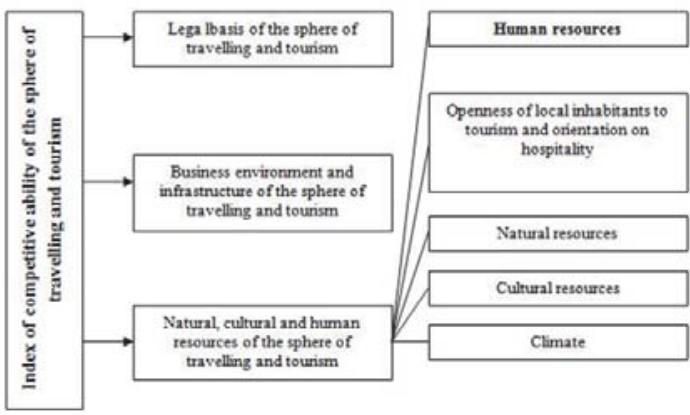

Image 1. Factorsof competitive ability of the sphere of travelling and tourism (Milić V. J., Jovanović S., Krstić B, 2011) 


\section{Staffing of Tourist Cluster Development}

The quality of personnel influences on the quality of services in tourist sphere and competitive ability of the branch. In this way, the process of stimulation of new work places formation must be linked with developing and taking steps for creation of conditions that contribute to:

increase of work force quality (educational programs of professional preparation and continuing education for and unemployed citizens, employment support and providing training for young population) and reaching balance between future demand and offer for specific professions at labor-market. There must be used a potential and experience of specialized leading higher institutions and secondary and primary professional education establishments in top sectors: tourism and service, construction and agriculture. Maximal including of local work force into project will make it possible to enhance positive economic effect from investments to region economics;

- creation of conditions for development of internal population mobility;

- enhancement of efficiency of special institutions functioning at labor-market (development of employment centers and resource centers).

Labor resources demand forecast in resort-recreational and related branches till 2025, based on calculation results of forecast model allows making a conclusion that region demand in labor resources will not be satisfied. According to forecast results, to develop tourist cluster there is a demand in the amount of 78526 people. Tourist industry development will stimulate development of related industries, demand of which will make up 167926 people until 2025 (image 2).

Involvement of qualified employers to work in NCFD, Krasnodar Krai and the Republic of Adygea from other regions of the Russian Federation or from abroad can solve problems for some time. Maximal multiplier effect of local economic development (not only resort-recreational industry) is possible, if created work places will be held by local staff. So, it is vital to create conditions for professional improvement and permanent training of local specialists concerning actual specialties and professions that can be provided while creating industrial educational cluster, formation of corporate universities and center of assessment and qualification certification in tourist-recreational industry.

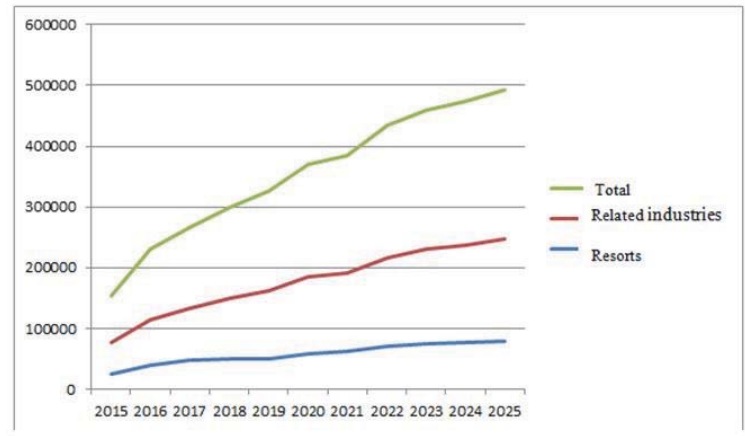

Image 2. Labor resources demand forecast in resort-recreational and related industries of regions of interest until 2025

The aim of creation of industrial educational cluster in the sphere of tourism and service on the basis of subjects of NCFD, Krasnodar Krai and the Republic of Adygea is improvement of territorial and industrial organization of resources of professional education system that is orientated on development of tourist cluster and related industries. To provide the set goal it is necessary to solve the following tasks:

1. To provide effective development of educational facility network according to requirements and needs of regional labor markets in the sphere of tourism and service;

2. To provide system integration of educational facilities of all levels in the sphere of tourism and service, and also related industries;

3. To create conditions for providing educational mobility of trainee and graduates;

Industrial educational cluster in the sphere of tourism and service - is a combination of professional education facilities and social partners for providing the need of regional labor market in the sphere of tourism and service, and also related industries. 
The principal scheme of the offered industrial educational cluster in the sphere of tourism and service is presented on the image 3. The creation of industrial educational cluster in the sphere of tourism and service is to perform associations in organizational form. The main advantages of such interrelation scheme are:

association members don't lose the status of legal body and remain independent organizations while acting within the frame of association;

association inclusion, as a member, doesn't leave organization without the right of entry into other associations, unions, communities of legal bodies;

- to join into association can different types of facilities, both budget and autonomous.

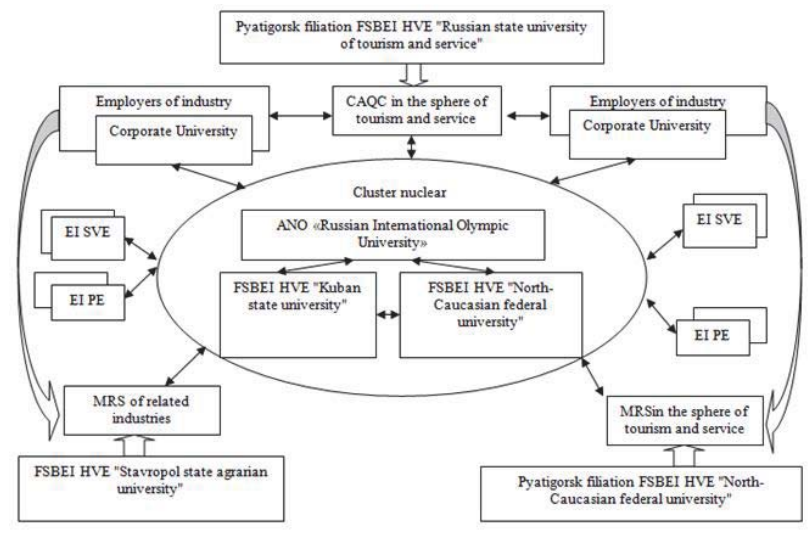

Image 3. Conceptual scheme of industrial educational cluster in the sphere of tourism and service on the basis of subjects of NCFD, Krasnodar Krai and the Republic of Adygea*

*Accepted contractions:

EI PE - educational institution of primary education;

EI SVE - educational institution of secondary vocational education;

FSBEI HVE - federal state budget educational institution of higher vocational education;

ANO - autonomous noncommercial organization;

CAQC - Center of assessment and qualification certification;

MRS - multiregional resource center

Within the frame of suggested model to identify the cluster nuclear - the leading IHLS of vocational education. The selection criteria of participants of education cluster nuclear must be orientated on list of existed academic base, preparation experience of specialists in the sphere of tourism and service, geostrategic situation of educational institutions. Consideration of these criteria make it possible to define 2 basic educational institutions of vocational education as members of cluster nuclear: FSBEI HVE "North-Caucasian federal university" (the Stavropol Territory) and FSBEI HVE "Kuban state university" (Krasnodar Krai) and autonomous noncommercial organization "Russian International Olympic University".

In the frame of strategy of labor resources engaging in NCFD, Krasnodar Krai and the Republic of Adygea, it is offered to create in each subject of RF, at the territories of which the tourist cluster construction is planned, educational institutions of primary (EI PE) and secondary vocational education (EI SVE), orientated on preparation of highly experienced personnel in the sphere of health resort business on methodological base of the Russian International Olympic University.

The creation of corporate universities that provide preparation, additional training and professional improvement in the specialties and professions of resort-recreational industry is one of the main mechanisms of strategy of labor resource engaging in NCFD, Krasnodar Krai and the Republic of Adygea. 


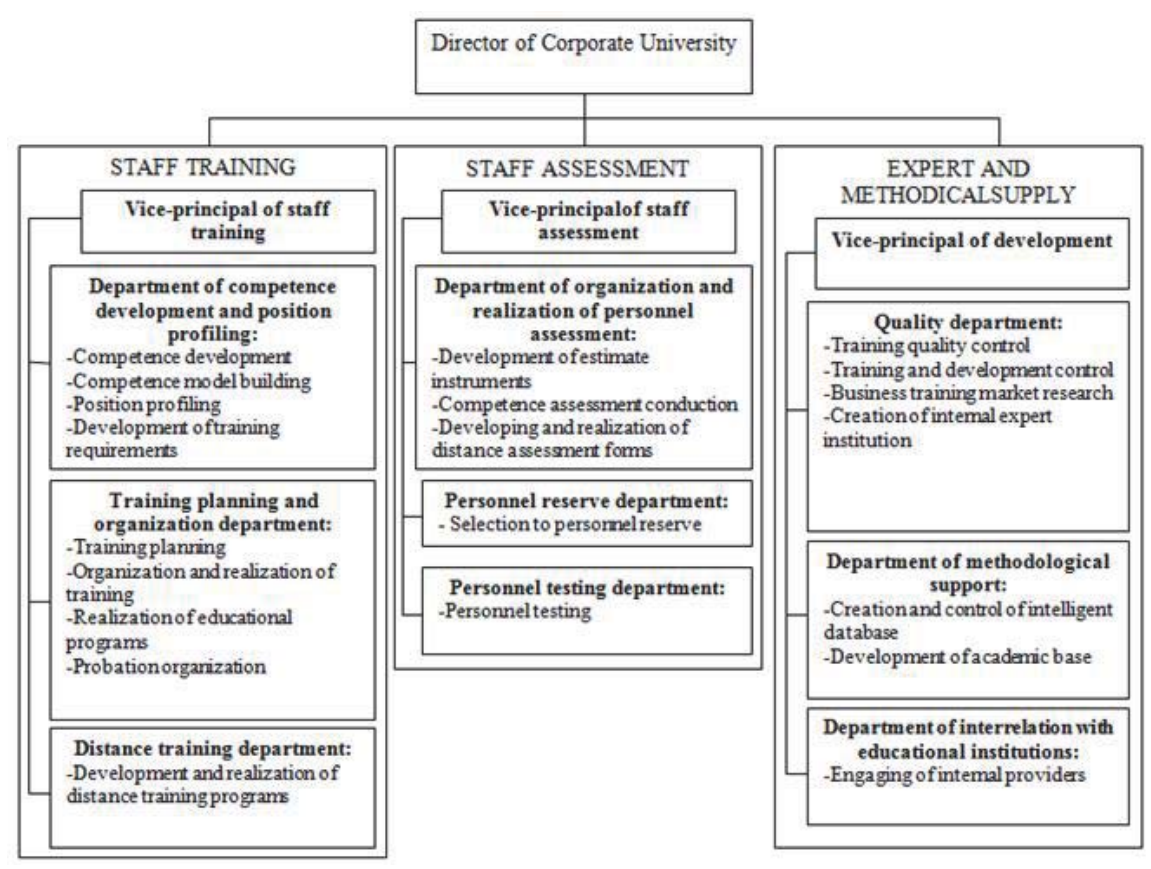

Image 4. Principal organizational and functional structure of Corporate University

Background for corporate universities creation is:

- $\quad$ necessity to build the system of long-term corporate studying and personnel development;

- non-conformity of specific features of student preparation in educational institutions to real needs of developing resort-recreational industry (overrepresentation of preparation of humanitarian workers with acute shortage of technical ones);

- necessity of preparation of highly experienced senior executives (investors in tourist industry have material opportunity to create and develop hotel infrastructure, but they are not ready to control it);

- increase and development of tourist cluster.

To reach target goals and tasks within the frame of corporate university formation, it is necessary to realize a complex of events in four main directions:

- creation of competitive educational programs;

- creation of infrastructure of generation and spread of knowledge, competitive technologies and innovations;

- creation of fully fledged system of partner relationships with educational organizations, scientific centers, commercial and noncommercial organizations; - formation of modern control system and infrastructure of corporate universities.

Recommended organizational and functional structure of corporate universities is presented on image 4. 


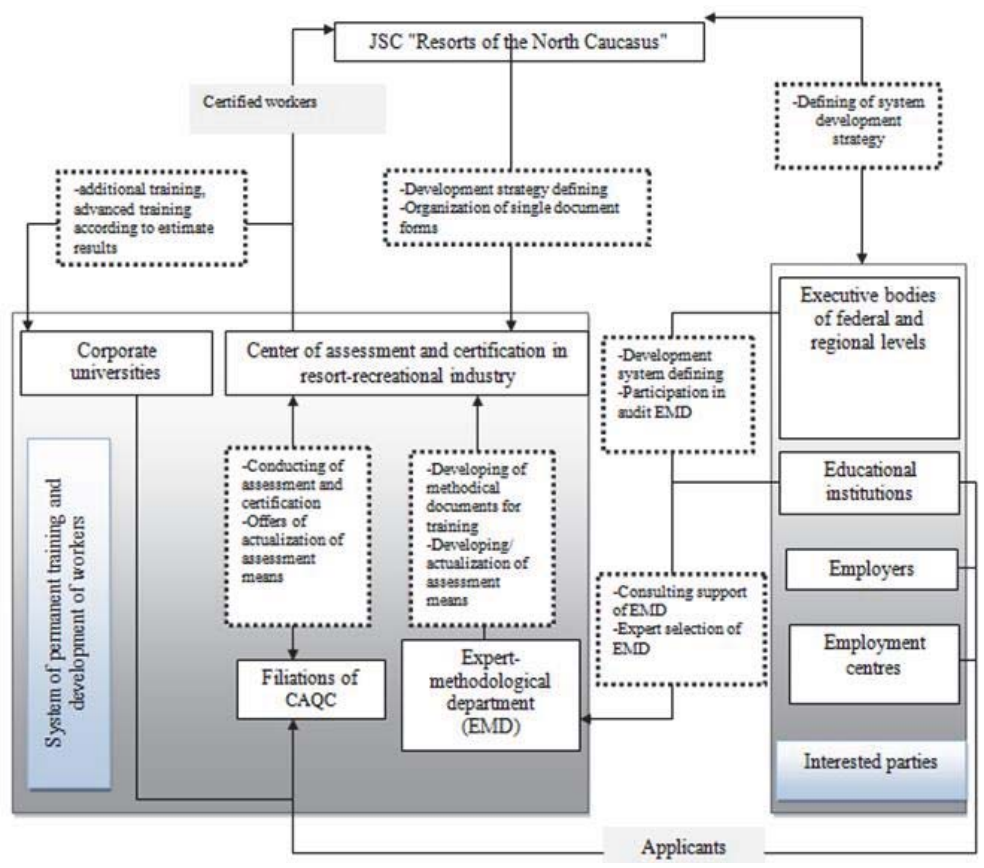

Image 5. Interrelation model of the Center of assessment and qualification certifications with executive bodies, educational facilities and other interested organizations

Tourists, who arrive at the territory of tourist cluster, must be provided with the level of specified services that correspond to world standards. That is why a competent and complex approach is vital for licensing and certification in touristrecreational industry.

The main purpose of the system of assessment and certification of qualifications in tourist-recreational industry is to provide assurance of correspondence of specialist in the sphere of tourist activities to certified requirements, rules, single standards and procedures of assessment and certification.

The main tasks of the Center of assessment and certification of qualifications (CAQC) in tourist-recreational industry:

assistance for enterprises, organizations and facilities of tourist-recreational industry in selection of qualified workers, certified according to professions in tourism;

stimulation of motivation of workers of tourist-recreational industry in the sphere of permanent vocational education and training;

creation of conditions for free transfer of work force around the territory of the Russian Federation and abroad; increase of competitive level of workforce in domestic Russian and international labor market.

An important point in organization activities of CAQC if providing its effective interrelation with other members of cluster space. The model of CAQC interrelation with abovementioned participants is presented on image 5 . The suggested model allows providing resort-recreational industry with personnel resources on the basis of complex approach, involving all interested parties in this process and maximal usage of territorial potential.

\section{Conclusion}

Conducted researches show the efficacy of cluster technologies in regional development control. Clustering usage in tourist sphere gives an incentive to development of educational sphere in the form of regional educational clusters. Therefore, a complex approach to solving problems of regional development is provided. An optimal positioning of new energy in economic space of two federal districts (SFD and NCFD) takes place within the frame of project, as well as search of new directions and methods of social-economic development of the region and country. The scale and content 
of project corresponds to the world level. In case of its successful realization Russia can receive about $\$ 100$ billion each year. In addition, it is important to mention that the project is gradually becoming a medium of new ideology transformation by means of clusters of stagnating system in dynamically developing in the whole, and complicated region, in particular.

\section{References}

Andersson T., Schwaag-Serger S., Sorvik J., Hansson E.W. The Cluster Porches White book, IKED, 2004. URL: http//www. competitiveness org/article/view/241/1.

Bergman E.M., Feser E.J. Industrial and Regional Clusters, Concepts and Comparative Applications, Regional Research Institute, WVU 1999. URL:http//www.rriwvu.edu/WebBook.

Enright Michael J et al/ Survey on the Characterization of Regional Clusters Initial Results Working Paper Institute of Economic Policy and Business Strategy Competitiveness Program University of Hong Kong and the Competitiveness Institute Barcelona, Spain 2000.

Markusen A. Sticky Places in Slippery Space. A Typology of Industrial Districts, Economic Geography 72(3), 1996.

Milić V. J., Jovanović S., Krstić B. Human Resources in tourism as a factor of its employment and competitiveness growth - comparative analysis of Serbia and surrounding countries. (Series: Economics and Organization Vol. 8, № 4, 2011, pp. 433 - 445).

Porter M.E. Competition - M.: Publishing house Williams, 2002. 496 c.

Rosenfeld, S.A. Bringing Business Clusters into the Mainstream of Economic Development, European Planning Studies, 5(1), 1997. 